\title{
OPPORTUNITIES FOR THE ENERGY SECTOR FROM UNCONVENTIONAL ENVIRONMENTAL ANALYSES AND SENSORS
}

\author{
ELENA CRISTINA RADA ${ }^{1,2}$ \\ ${ }^{1}$ Department of Theoretical and Applied Sciences, University of Insubria, Varese, Italy \\ ${ }^{2}$ Department of Civil, Environmental and Mechanical Engineering, University of Trento, Italy
}

\begin{abstract}
The typical problems of air pollution to be faced with in many anthropized areas, even where the environment is protected by modern approaches, make it strategic the integration of conventional methodologies for air quality monitoring with unconventional ones proposed in the sector but not yet considered suitable to be official. By these integrated approaches, it is possible to identify single or multiple sources responsible of local air pollution (also in form of peaks of pollution). The additional information generated by unconventional sampling and/or sensors can be used by decision makers for setting strategies of reduction of the impact of specific sources, when these last ones are responsible of an unsustainable incidence in contributing to the local air pollution. A few case studies were selected and have been analysed to discuss about the advantages in integrating the conventional monitoring tools with other ones that are innovative (not alternative) but not official yet. The selected case studies belong to two categories: a) the first one concerns the identification of the role of a single source in contributing to the local air pollution, b) the second one concerns the assessment of the role of a sector in the local presence of air pollutants. The cases belong to the civil and the industrial sectors. Diffused and conveyed emissions are analysed depending on the case.
\end{abstract}

Keywords: air, biomass, energy, environmental, highway, industrial, pollution, sensors, transport, waste.

\section{INTRODUCTION}

The present European Union approach for air quality management cannot avoid problems of air pollution in anthropized areas [1]-[3]. For that reason, it is necessary to integrate conventional methodologies of air quality monitoring with unconventional ones able to identify the sources contributing significantly to local pollution [4]-[7]. In this frame, the energy sector is often seen as a primary responsible of air quality problems even if its contribution has been lowered [8]-[10]. That depends also on memories of highly polluting plants that characterized even Europe decades ago.

Unconventional methodologies concern both analyses generated at laboratory level (thanks to a previous sampling) and values generated in field (e.g. thanks to innovative environmental sensors able to generate data at low cost). The produced additional information allows decision makers setting specific strategies oriented to reduce the impact of specific sources having an unsustainable incidence in contributing to the local air pollution (also in form of peaks of concentrations).

In this article, the sector of energy is considered from a wide perspective: not only centralized plants for energy generation but also diffused emitters based on fuel consumption as the automotive sector. Thus, a few case studies were selected and are presented to analyse the advantages in integrating conventional monitoring tools with other ones not yet recognized as suitable for generating official data (i.e. not generated according to the regulations in force). 


\section{MATERIALS AND METHODS}

Among the case studies that could be of interest both for the civil and the industrial sectors, are the:

- identification of the role of a single source in contributing to the local air pollution;

- assessment of the role of a sector in terms of contribution to the local presence of air pollutants.

Other cases of potential interest have been discarded when the evolution of the technology makes it no longer necessary an additional control based on an unconventional approach. This is the case, for instance, of the conversion of a composting plant to a biomethane plant based on anaerobic digestion and biogas refining. The modifications introduced in the system significantly decrease and prevent the potential problems of impact. In this case, data requested from the regulation in force are adequate to take the environment under control.

Another group of case studies are not included in this article because of related to human exposure to air pollutants that are not generated from energy sources exploitation.

\section{RESULTS AND DISCUSSION}

The survey of case studies of interest, taken from direct experiences performed by the Department of Civil, Environmental and Mechanical Engineering of the University of Trento, in some cases with the collaboration of the University of Insubria, gave the following list:

- $\quad$ case 1: steel making plant

- case 2: thermochemical plant for energy recovery from residual municipal solid waste

- case 3: co-combustion of waste in cement factories (thermally dried sewage sludge)

- case 4: wood burning (domestic combustion and district heating)

- case 5: highway (polluting emissions to air from vehicles)

- case 6: multi-parameter personal devices for individual human exposure detection

Case 1: Diffused emissions from an industrial activity are managed differently from the conveyed ones when an authorisation must be released. Adopted criteria are often based on assumptions and not on measurements because the way of release into the atmosphere sometimes does not allow direct quantification. For this reason, they may be underestimated in the phase of plant authorization. An example comes from the sector of steel making plants. In the frame of the overall releases, a significant stream of pollutants can come from the secondary activities not related to conveyed and treated emissions.

A case study was selected to this concern. It is related to the adoption of two unconventional approaches in the case of a study of a steel making plant in an Italian valley [11], [12]:

- one was adopted for the measurement and analysis of the deposition of pollutants around the plant, specifically polychlorinated dibenzo-p-dioxins and dibenzofurans (PCDD/Fs) and polychlorinated biphenyls (PCBs)

- the other is related to the indirect verification of human exposure to $\mathrm{PCDD} / \mathrm{Fs}$ and PCBs by the characterization of the sewage sludge produced in the area.

The generated information supports decision makers when checking if specific strategies against diffused emissions should be adopted. 
Atmospheric depositions of $\mathrm{PCDD} / \mathrm{Fs}$ and PCBs were monitored at three sites in the vicinity of a steel making plant. High variability in the deposition of PCDD/Fs was observed. The influence of the plant was visible at two sampling sites. However, as a study on the congener profiles demonstrated, wood burning for domestic heating was an additional source of $\mathrm{PCDD} / \mathrm{Fs}$ for the area under investigation, interfering with the attempt of characterizing the emissions from the steel plant. The influence of the plant, in terms of PCDD/F deposition, was not visible at the most distant site ( $2 \mathrm{~km}$ far from the plant). Here, an extremely high peak of PCDD/F deposition was measured during a winter period; the comparison between the congener distribution of $\mathrm{PCDD} / \mathrm{Fs}$ observed in this sample and the fingerprints of different sources allowed the attribution of such anomalous peak to a possible episode of domestic combustion of waste.

With the attempt to find a better correlation between deposition to soil and emissions from the plant, the congener distribution of PCBs was studied too: the PCB profiles observed at the three sites well reproduced the average profile found in samples of ash retained by the bag filter of the plant. For this reason, the monitoring of PCB deposition is an interesting starting point to calibrate dispersion models for the assessment of the impact of steel making activities.

Apart from the cited Italian case, steel making plants can be the primary contributors of $\mathrm{PCDD} / \mathrm{Fs}$ and PCBs in an area. Taking into account this role, it is clear that an approach acting as sentinel of anomalous human exposure is useful. An opportunity is given by sewage sludge. Indeed, a continuous anomalous exposure to PCDD/Fs and PCBs through the typical pathways (diet, ingestion, dermal contact, inhalation) could be detected by the sewage sludge if the population of interest is the only one serviced by the local wastewater treatment plant [2]: the human body is not a destroyer of PCDD/Fs and PCBs and the wastewater plants concentrate them in the sludge. The approach is made partially complex from the presence of a domestic source of such pollutants: detergents. However, this contribution becomes secondary in the sewerage when the population is highly exposed.

Summing up, the above presented experience pointed out that:

- deposimeters can allow the detection of a prevalent polluter when a pre-study of the area has been performed;

- $\quad$ sewage sludge can act as sentinel when a wastewater treatment plant serviced only an exposed population.

Case 2: Thermochemical plants for co-generation from waste exploitation improved significantly their environmental performances in the European Union two decades ago thanks to a clear modification of the emissions regulation. In order to demonstrate that a modern plant has a low impact on the territory, conventional and unconventional measurements can be made. Typically the conventional ones (e.g. measurements from a punctual monitoring station detecting conventional parameters) are not always considered sufficient from the local population. Also in this case deposimeters can play the role of detectors of prevalent sources of PCDD/Fs. If we consider that a modern plant must have a negligible contribution to the concentration in air, the fact that an incinerator could be recognised as main source is an information very important for the body in charge for air quality control: this should be a demonstration that something wrong happened and something must be done to correct the management of the plant.

Apart from that, another important parameter can be deeply verified thanks to unconventional air quality sensors. This is the case of $\mathrm{NO}_{\mathrm{x}}$. Often the yearly average of the contribution of the plant to the value of $\mathrm{NO}_{\mathrm{x}}$ is not critical. Some problems can come from 


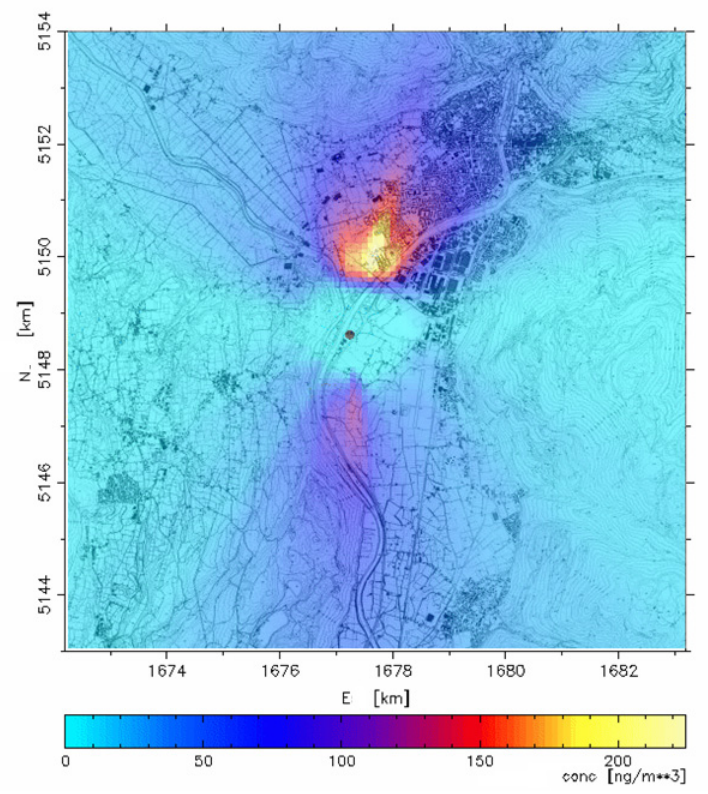

Figure 1: Map of the incidence of the Bozen incinerator (yearly average of $\mathrm{NO}_{\mathrm{x}}$ ) [13].

the parameter $\mathrm{NO}_{2}$ because of the potential presence of peaks at hourly level during unfavourable meteorological conditions that could be responsible of the overcoming of the regulation limit. In this case, the availability of low cost sensors for $\mathrm{NO}_{2}$ placed in the territory could act as sentinel. For instance, when the recorded values point out a growth of the hourly value of $\mathrm{NO}_{2}$ in selected areas, the plant manager could activate an alternative approach for $\mathrm{NO}_{2}$ emission reduction, e.g. increasing the addition of urea or ammonia to the SNCR or SCR present in the off-gas treatment line. In Fig. 1 [13], a map reporting the yearly contribution of $\mathrm{NO}_{\mathrm{x}}$ in the case of the Bozen plant (Italy) is presented. Few low-cost sensors of $\mathrm{NO}_{2}$ could be placed in the Northern area of highest impact. Low cost sensors must be chosen depending on the accuracy required. Taking into account the present availability of technologies for $\mathrm{NO}_{2}$ sensors, the ones based on a thick film seem to be the best option. Costs decrease significantly compared to a conventional method: few thousands of Euros per point of measurement including sensor, datalogger and transmitter. The compactness of the system allows an easy repositioning if necessary.

Case 3: Co-combustion of dried sludge in cement factories can increase the emission of $\mathrm{NO}_{\mathrm{x}}$ of the plant because of the oxidation of Nitrogen present in the volatile solids of sewage sludge. The problem is more relevant than in the past because of the increased efficiency of Nitrogen removal that characterises modern wastewater treatment plants. In case the local availability of meteorological data makes it impossible a highly reliable forecasting of the local effect of this additional contribution at the stack, a solution could be the positioning of low cost sensors for $\mathrm{NO}_{2}$ detection according to a strategy that could be based on simplified dispersion models. $\mathrm{NO}_{2}$ is the form of $\mathrm{NO}_{\mathrm{x}}$ more relevant for its effects on the human health. Data generable are interesting in particular in winter, when all the potential contributors of $\mathrm{NO}_{\mathrm{x}}$ are active (because of domestic heating) and the climatology is often less favourable. This case has been discussed in Trentino (Italy) when the local authorities demonstrated an 
interest to an agreement with a cement factory for co-combustion of dried sewage sludge. Locally a request rose aiming to an additional system of control at ground level acting as a sentinel. In case of critical values of $\mathrm{NO}_{2}$ in the air where the population live, a mitigation strategy could be the temporary suspension of sewage sludge burning, replaceable by conventional coal (that remains always the primary fuel of the plant). The initiative could not see the real scale because of the closure of the industrial plant in consequence of the economic crisis of the building sector in Italy.

Case 4: Often small-medium enterprises in the crafts sector use wood as fuel; moreover, domestic heating in some regions is based on wood burning. As wood combustion can be locally highly impacting, specific approaches suitable to identify the local role of wood in the air quality deterioration is necessary. A case study related to the use of Levoglucosan (LG) as quantitative tracer of wood combustion activities concerned the Province of Trento (Italy) [14]. The generated information allowed decision makers verifying if specific strategies of prevention/treatments must be adopted locally. The principle is to analyse the particulate matter (PM) filters that are used for PM conventional monitoring to check the presence of LG, a substance generated only from wood combustion in relationship with the value of PM. A statistic elaboration of the values of LG and PM produced in winter and in summer allows generating linear regressions suitable to check which could be the concentration of PM when LG is virtually zero (that is in case wood contribution is zero). In Trentino this approach demonstrated that about half of the PM concentration comes from the wood combustion sector. Decision makers used this information to start a wide programme for optimising the use of wood.

Case 5: Truck transport of goods by highway and traffic in general can have a local relevant impact in terms of air pollution. Emissions are released mainly both from trucks and from cars. A direct and detailed measurement of the presence of specific pollutants along a highway can contribute to clarify the potential and actual problems of pollution and makes available data for forecast models. The selected case study is related the use of low cost sensors for $\mathrm{NO}_{2}$ measurement in the frame of a EU Life+ project, during different speed limit situations tested in the A22 highway crossing the Province of Trento (Italy). This approach allows decision makers checking if commercial traffic plays a relevant role and if it makes sense to reduce the highway speed limits in some conditions. The core idea of the project concerns the generation of additional air quality data by low cost sensors of $\mathrm{NO}_{2}$ to calibrate a complex model of air quality forecasting, linked to traffic data and meteorological data [15]. After some years of "addition feed" the system will have to go on only using conventional data.

Case 6: Previously explained case-studies are related to the concept of measuring a parameter in a specific fixed site. An alternative to this approach is the personalised monitoring at individual level, that the evolution of the environmental sensors seems to make closest to be performed at commercial scale.

Some parameters related to the comfort concept are already suitable at the required accuracy (e.g. temperature, humidity, pressure). The limitations today are related to the air quality parameters. $\mathrm{CO}$ can be already measured at level of individual exposure but its significance is basically related to anomalous indoor releases for bad combustion of fuels. Other parameters as $\mathrm{NO}_{2}, \mathrm{O}_{3}$, benzene have some limitations when the system must be suitable at costs sustainable at individual level. An analysis of some devices of this category have been made recently focusing in particular on benzene [16].

\section{CONCLUSIONS}

An overview of the potential uses of what seen in the case studies is presented in Table 1. 
Table 1: Overview of the analysed cases.

\begin{tabular}{lcl}
\hline \multicolumn{1}{c}{ Device } & Emission of interest & \multicolumn{1}{c}{ Notes } \\
\hline $\begin{array}{l}\text { Deposimeter for } \\
\text { organic } \\
\text { micropollutants }\end{array}$ & Diffused & $\begin{array}{l}\text { Additional information can be } \\
\text { generated to check the local role of a } \\
\text { diffused source of micro-pollutants }\end{array}$ \\
\hline $\begin{array}{l}\text { Low cost } \\
\text { environmental } \\
\text { sensors (thick film) } \\
\text { for } \mathrm{NO}_{2}\end{array}$ & Conveyed & $\begin{array}{l}\text { Additional information can be } \\
\text { generated to check the local role of a } \\
\text { source of } \mathrm{NO}_{2} \text { in order to modify the } \\
\text { management strategy of the off gas } \\
\text { treatment line }\end{array}$ \\
\hline $\begin{array}{l}\text { Low cost } \\
\text { environmental } \\
\text { sensors (thick film) } \\
\text { for } \mathrm{NO}_{2}\end{array}$ & Conveyed & $\begin{array}{l}\text { Additional information can be } \\
\text { generated to check the local role of a } \\
\text { source of } \mathrm{NO}_{2} \text { in order to modify the } \\
\text { management strategy of co-combustion }\end{array}$ \\
\hline $\begin{array}{l}\text { Wood combustion } \\
\text { tracer (LG) }\end{array}$ & Multiple conveyed sources & $\begin{array}{l}\text { The methodology is generally not } \\
\text { known in the official laboratories }\end{array}$ \\
\hline $\begin{array}{l}\text { Sewage sludge } \\
\text { analysis as sentinel }\end{array}$ & All & $\begin{array}{l}\text { Suitable only when a wastewater } \\
\text { treatment plant services only the } \\
\text { exposed population }\end{array}$ \\
\hline $\begin{array}{l}\text { Multiparameter } \\
\text { personal devices }\end{array}$ & & \begin{tabular}{l} 
Ready only for CO at viable costs \\
\hline
\end{tabular} \\
\hline
\end{tabular}

All the presented cases are relevant from the social point of view. That means unconventional air quality monitoring can help in the management of the relationships with the territory where a plant is placed, if this is the case. Indeed, one of the typical requests of the groups opposing the construction or the presence of an industrial plant is the integration of conventional monitoring, considered not sufficient for the characterization of the area.

Moreover, the integration of conventional approaches allows a personalization of data collection making more reliable the decisions on the management of the environment.

All the considered methods but one are economically viable if compared with the effort made with the conventional monitoring. The exception is the multi-parameter system that is not yet ready for commercial applications (apart from $\mathrm{CO}$ ).

The variety of the devices and approaches makes it necessary an effort in updating laboratory methodologies, sampling devices, electronic tools and more in general expertise in the management of part of that on field. To this concern, a wider sharing of the growing expertise in this sector, through scientific articles, is desirable.

\section{REFERENCES}

[1] Caggiano, R., Calamita, G., Sabia, S. \& Trippetta, S., Biomonitoring of atmospheric pollution: a novel approach for the evaluation of natural and anthropogenic contribution to atmospheric aerosol particles, Environmental Science and Pollution Research, 24(9), pp. 8578-8587, 2017.

[2] Schiavon, M., Redivo, M., Antonacci, G., Rada, E.C., Ragazzi, M., Zardi, D. \& Giovannini, L., Assessing the air quality impact of nitrogen oxides and benzene from road traffic and domestic heating and the associated cancer risk in an urban area of Verona (Italy), Atmospheric Environment, 120, pp. 234-243, 2015.

[3] Rada, E.C., The sustainable city and air pollution, WIT Transactions on Ecology and the Environment, 191, pp. 1369-1380, 2014. 
[4] Tran, T.V., Dang, N.T. \& Chung, W.Y., Battery-free smart-sensor system for real-time indoor air quality monitoring, Sensors and Actuators, B: Chemical, 248, pp. 930-939, 2017.

[5] Asaduzzaman, S. \& Ahmed, K. Proposal of a gas sensor with high sensitivity, birefringence and nonlinearity for air pollution monitoring, Sensing and Bio-Sensing Research, 10, pp. 20-26, 2016.

[6] Yi, W.Y., Lo, K.M., Mak, T., Leung, K.S, Leung, Y. \& Meng, M.L., A survey of wireless sensor network based air pollution monitoring systems, Sensors, 15(12), pp. 31392-31427, 2015.

[7] Rada, E.C., Ragazzi, M., Brini, M., Marmo L., Zambelli, P., Chelodi, M. \& Ciolli, M., Perspectives of low-cost sensors adoption for air quality monitoring, UPB Scientific Bulletin, Series D, 74(2), pp. 243-250, 2012.

[8] Lott, M.C., Pye, S. \& Dodds, P.E., Quantifying the co-impacts of energy sector decarbonisation on outdoor air pollution in the United Kingdom, Energy Policy, 101, pp. 42-51, 2017.

[9] Chen, Y., He, L., Li, J., Cheng, X. \& Lu, H., An inexact bi-level simulationoptimization model for conjunctive regional renewable energy planning and air pollution control for electric power generation systems, Applied Energy, 183, pp. 969983, 2016.

[10] Crippa, M., Janssens-Maenhout, G., Dentener, F., Guizzardi, D., Sindelarova, K., Muntean, M., Van Dingenen, R. \& Granier, C., Forty years of improvements in European air quality: Regional policy-industry interactions with global impacts, Atmospheric Chemistry and Physics, 16(6), pp. 3825-3841, 2015.

[11] Rada, E.C., Ragazzi, M. \& Schiavon, M., Assessment of the local role of a steel making plant by POPs deposition measurements, Chemosphere, 110(1), pp. 53-61, 2014.

[12] Rada, E.C., Schiavon, M. \& Ragazzi, M., Seeking potential anomalous levels of exposure to PCDD/Fs and PCBs through sewage sludge characterization, Journal of Bioremediation and Biodegradation, 5(8), pp. 1-10, 2013.

[13] DICAM, 2001. Study of the emissions, of the diffusion in the atmosphere and of the deposition at ground level of the pollutants emitted by the incinerator of Bozen. University of Trento (in Italian).

[14] Rada, E.C., Ragazzi, M. \& Malloci, E., Role of levoglucosan as a tracer of wood combustion in an alpine region. Environmental Technology, 33(9), pp. 989-994, 2012.

[15] BrennerLec, http://brennerlec.life/. Accessed on: 2 Mar. 2017

[16] Dalla Valle, L., Rada, E.C., Ragazzi, M. \& Caraviello, M., Smart monitoring of benzene through an urban mobile phone network, International Journal of Sustainable Development and Planning, 12(3), pp. 552-558, 2017. 